\title{
Polikistik over sendromlu kadınlarda, Roma III teşhis kriterlerine göre fonksiyonel dispepsi sıklığı
}

\author{
The prevalence of functional dyspepsia in women with polycystic ovary syndrome according to the \\ Rome III diagnostic criteria
}

Erol ÇAKMAK ${ }^{1}$, Fettah ACIBUCU ${ }^{2}$

Cumhuriyet Üniversitesi Tip Fakültesi, ${ }^{1}$ Gastroenteroloji Bilim Dah, Sivas

Sivas Numune Hastanesi, ${ }^{2}$ Endokrinoloji Kliniği, Sivas

Giris ve Amaç: Polikistik over sendromu reprodüktif çağdaki kadınlarda en sık görülen endokrin hastalıktır. Fonksiyonel dispepsi, genel popülasyonda yaygın görülen organik neden olmaksızın dispeptik semptomların eşlik ettiği fonksiyonel gastrointestinal bozukluktur. Daha önceki çalışmalarda polikistik over sendromlu hastalarda fonksiyonel dispepsi sıklığı ve aralarındaki ilişki araştırılmamıştır. Biz bu çalışmada polikistik over sendromlu hastalarda fonksiyonel dispepsi sıklığını ve aralarındaki ilișkiyi araștırmayı amaçladık. Gereç ve Yöntem: Çalışmamız prospektif olarak planlandı ve reprodüktif çağdaki 73 polikistik over sendromlu hasta ve 67 sağllklı kontrol denek alındı. Bu deneklerin gastrointestinal semptomları anketle saptandı. Deneklerin boy, kilo değerleri kayıt edildi ve serum açlık glukoz, insülin, kortizol, prolaktin, troid uyarıcı hormon, folikül uyarıcı hormon, luteinleştirici hormon, total testosteron, dehidroepiandrosteron sülfat düzeylerine bakıldı. Deneklerin insülin direnci ve vücut kitle indeksi değerleri hesapland1. Bulgular: Çalışmaya alınan polikistik over sendromu ve sağlıklı kontrol grubu arasında yas açısından anlamlı fark bulunamadı (22.1 4.1 vs. $23.5 \pm 5.1$ yıl,sırasiyla $p>0.05$ ). Gruplar serum total testosteron, dehidroepiandrosteron sülfat ve luteinleștirici hormon düzeyleri açısından karşılaştırıldığında aradaki fark önemli bulundu ( $p=0.001, p=0.001, p=0.038$, siraslyla). Polikistik over sendromlu 73 hastanin 38'inde (\%52.1) ve kontrol grubunda 67 deneğin 16'sında (\%23.9) fonksiyonel dispepsi mevcut idi. Fonksiyone dispepsi sıklığı polikistik over sendromu hastalarında sağlıklı kontrol deneklerden daha yüksek bulundu ( $p=0,006)$. Fonksiyonel dispepsisi olan polikistik over sendromlu hastalar, fonksiyonel dispepsi subgrupları açısından karşılaştırıldığında postprandiyal distres sendromu sağlıklı kontrol grubuna kıyasla sık $(p<0.05)$ iken epigastrik ağrı sendromu için sağlıklı kontrol grubu ile arasinda istatistiksel fark yok idi ( $p>0.05)$. Polikistik over sendromu hastalarında vücut kitle indeksi, serum açlık kan glukozu, insülin, kortizol, prolaktin, troid uyarıcı hormon, folikül uyarıcı hormon ve insülin direnci indeksi sağlıklı kontrol grubu ile karșılaștırıldığında aralarında fark bulunamadı ( $p>0.05)$. Sonuç: Polikistik over sendromlu hastalarda, fonksiyonel dispepsi ve dispepsi subgrubu olan postprandial distress sendromu siklı̆g sağlıklı kontrol grubu ile karşılaştırıldığında yüksek saptandı. Polikistik over sendromlu hastalarda, fonksiyonel dispepsi ve subgrubu olan postprandial distress sendromun sık görülmesinin hiperandojenizm ile ilişkili olduğu düşünüldü.

Anahtar kelimeler: Dispepsi, polikistik over sendromu, postprandiyal distres sendromu, epigastrik ağn sendromu

\section{GIIRISS}

Polikistik over sendromu (PKOS) reprodüktif yaştaki kadınlarda sık görülen irregüler menses, hiperandrojenizm ve polikisitik overler ile karekterize endokrin bir bozukluktur. PKOS teşhisde kullanılan kriterlere ve coğrafi bölgelere göre sıklığı
Background and Aims: Polycystic ovarian syndrome is the most frequently seen endocrine disease in women of reproductive age. Functional dyspepsia is a functional gastrointestinal disorder that is commonly seen in the general population, accompanied by dyspeptic symptoms without an organic cause. Previous studies have not investigated the frequency of functional dyspepsia in patients with polycystic ovarian syndrome and the relationship between them. In this study, we aimed to determine the frequency of functional dyspepsia in patients with polycystic ovarian syndrome and to investigate the relationship between them. Materials and Methods: Our study was prospectively planned, and 73 patients with polycystic ovarian syndrome and 67 healthy control subjects of reproductive age were included. Gastrointestinal symptoms were detected via survey conducted on these subjects. Height and weight values of the subjects were recorded, and serum fasting glucose, insulin, cortisol, prolactin, thyroid stimulating hormone, follicle stimulating hormone, luteinizing hormone, total testosterone, and dehydroepiandrosterone sulfate levels were measured. Homeostasis model assessment of insulin resistance and body mass index values of the subjects were calculated. Results: There was no significant difference in age between the study group and the healthy control group $(22.1 \pm 4.1$ vs. $23.5 \pm 5.1$ years, respectively, $p>0.05$ ). When the groups were compared in terms of serum total testosterone, dehydroepiandrosterone sulfate, and luteinizing hormone levels, the differences were found to be statistically significant ( $p=0.001, p=0.001$, and $p=0.038$, respectively). Functional dyspepsia was present in $38(52.1 \%)$ of the 73 patients with polycystic ovarian syndrome and 16 of the 67 (23.9\%) patients in the control group. The frequency of functional dyspepsia was higher in patients with polycystic ovarian syndrome than in healthy control subjects ( $p=0.006$ ). In patients with polycystic ovarian syndrome with functional dyspepsia, when functional dyspepsia subgroups were compared, postprandial distress syndrome was more frequent than in the healthy control group $(p<0.05)$, while no statistically significant difference was found between the healthy control group and the group with epigastric pain syndrome $(p>0.05)$. There was no significant difference in body mass index, serum fasting glucose, insulin, cortisol, prolactin, thyroid stimulating hormone, follicle stimulating hormone, and homeostasis model assessment of insulin resistance index in polycystic ovarian syndrome when patients were compared with the healthy control group $(p>0.05)$. Conclusion: In patients with polycystic ovarian syndrome, the frequency of functional dyspepsia and its subgroup, postprandial distress syndrome, was found to be higher than in the healthy control group. In patients with polycystic ovarian syndrome, the cause of the frequent cooccurrence of functional dyspepsia and its subgroup, postprandial distress syndrome, was thought to be hyperandrogenism.

Key words: Dyspepsia, polycystic ovarian syndrome, postprandial distress syndrome, epigastric pain syndrome

\%6-25 oranında değişkenlik gösterir (1). PKOS teşhisinde en sık Rotterdam kriterleri kullanılır. Bu kritere göre aşırı androjen ve ilişkili bozukluklar dışlandıktan sonra klinik ve/veya biyokimyasal hiperandrojenizm, ovulatuvar disfonksiyon ve 
ultrasonografik polikistik over morfolojisi kriterlerinden en az ikisinin olması ile tanı konulur $(1,2)$. PKOS'u dislipidemi, insülin rezistansı, yağlı karaciğer, infertilite, metabolik sendrom, kardiyovasküler hastalıklar gibi metabolik bozukluklara yol açan heterojen bir hastalıktır. PKOS, obezite ve diabetes mellitus hastalarında oldukça sık görülür. Obezite şiddetinin artışı ile PKOS sıklığı artar ve bu hastalarda kilo kaybı ile birlikte hastalı̆̆ı şiddetinde azalma olur (2,3).

Fonksiyonel dispepsi (FD) de PKOS hastalığı gibi toplumda yaygın görülen bir hastalıktır. Bu hastalık coğrafi değişkenlik göstermekle birlikte genel popülasyonda sıklığı \%20-40'dır (4). Bu hastalıkta risk faktörlerinin başında psikolojik rahatsızlıklar, yaşam tarzı alışkanlıkları, kötü sosyoekonomik durum, sigara, aşırı kafein tüketimi ve non-steroidal anti-inflammatuvar ilaç kullanımı yer alır $(4,5)$. Roma III kritelerine göre FD hastalarında postprandial doygunluk, erken doyma, epigastrik ağrı ve epigastrik yanma en sık görülen semptomlardır. Fonksiyonel dispepsi teşhisi için yapısal nedenlerin dışlanması için üst gastrointestinal endoskopi yapılması gerekir (5). Roma III kritelerine göre FD semptomları postprandiyal distres sendromu (PDS) ve epigastrik ağn sendromu (EAS) olmak üzere iki subgrup olarak kategorize edilir. Gastrointestinal sistemin diğer fonksiyonel bozuklukları olan gastroözofageal reflü ve irratabl barsak sendromu ile FD örtüşebilir $(5,6)$.

Günümüzde PKOS ve FD genel popülasyonda oldukça yaygın görülen bozukluklardır. Literatürde PKOS'lu hastalarda FD sıklı̆̆ ile ilgili herhangi bir çalışma yok idi. Amacımız PKOS'lu hastalarda FD sıklığını araştırmak ve aralarındaki ilişkiyi değerlendirmek idi.

\section{GEREC ve YONTEM}

Ekim 2015 ile Mart 2016 tarihleri arasında Sivas Numune Hastanesinde teşhisi konulan reprodüktif yaştaki (age: 1549) 73 PKOS'lu ve yaş-vücut kitle indeksi (VKI) eşleştirilmiş 67 sağlıklı kontrol kadın çalışmaya dahil edildi. Deneklerde PKOS teşhisi 2003 Rotterdam kriterlerine göre; oligo veya anovulasyon, klinik ve/veya biyokimyasal hiperandrojenizm bulguları, ultrasonografik muayenede polikistik overler saptanması koşullarından ikisini karşılaması durumunda konuldu. Ayrica bu hastalardan konjenital adrenal hiperplazi, Cushing sendromu, androjen salgilayan tümör, idiyopatik hirsutizm, hiperprolaktinoma olan hastalar çalışmaya dahil edilmedi (7). Kontrol denekleri, düzenli menstrüel siklusu olan ve aşırı androjen bulguları olmayan sağlıklı kadınlardan oluşturuldu. Diabetes mellitus, kanser, troid, respiratuvar, karaciğer, böbrek hastalıklar, otoimmün bozuklukları olanlar ve oral kontraseptif ilaç kullananlar çalışma dışı bırakıldı.

Deneklerin yaş, boy ve kilo gibi demografik bilgileri kayıt edildi. VKI vücut ağırlı̆̆ının boyun karesine bölünerek (kg/ $\mathrm{m}^{2}$ ) hesaplandı. Tüm deneklerin klinik ve biyokimyasal olarak hiperandrojenizm bulguları değerlendirildi. Klinik hiperandrojenizm hirsutizm, akne, androjenik alopesi ve virilizasyon olarak kabul edildi. Ferriman-Gallwey skoru sekizden daha fazla olanlarm hirsutizmi var olarak kabul edildi. Biyokimyasal hiperandrojenizm ise androjenlerin yüksekliği olarak tanımlandı (3). Tüm deneklerin 6-10 MHz sıklı̆̆ında transducer (Aplio 300, Toshiba, Japan) kullanılarak abdominal ultrasonografisi yapildi. Ultrasonografide herbir overde 2-9 mm çapında 12 veya daha fazla foliküllerin bulunması, ve/veya ovarian volümün $10 \mathrm{~mL}$ fazla olması polikistik over olarak kabul edildi (7). Hastalardan siklusun 3-5 gününde gece (>10 saat) açlıktan sonra folikül uyarıcı hormon (FSH), luteinleştirici hormon (LH), total testosteron, dehidroepiandrosteron sülfat (DHEAS), prolaktin, kortizol, troid uyarıcı hormon (TSH), açlık kan şekeri ve insülin seviyeleri çalışıldı. Hastaların insülin rezistansı için (açlık insülin $\mu \mathrm{U} / \mu \mathrm{L}) \times($ açlık kan şekeri mg/dL) / 450 formülü kullanılarak homeostasis model assessment of insülin resistance (HOMA-IR) değerleri hesaplandı (8).

Çalışmamız Helsinki Deklarasyon prensiplerine uygun olarak yapılmış, ilgili hastanelerin etik kurullarından onay alınmış ve çalışmaya katılan hastalardan bilgilendirilmiş olur alınmıştır.

\section{Çalıșma Protokolü}

Çalışmaya reprodüktif yaştaki kadınlardan Roma III kriterlerine uygun normal büyüklükteki yemekten sonra meydana gelen rahatsız edici postprandial doygunluk, erken doyma, epigastrik ağr veya epigastrik yanma gibi semptomlardan bir veya daha fazlasına son 3 ayda sahip olan ve semptomları tanıdan 6 ay öncesinde başlayan hastalar çalışmaya dahil edildi. Ayrıca yapılan üst endoskopik muayenede organik bozukluğu olan denekler çalışmaya alınmadı. Ayrıca reprodüktif yaştaki kadınlardan FD olan denekler, FD subgrubları arasındaki farklılıkları değerlendirebilmek için Roma III kriterlerine göre PDS ve EAS olmak üzere iki subgrupta kategorize edildi. PDS için sıradan ölçekli yemeklerden sonra postprandial doygunluk veya düzenli yemek bitimine engel erken doyma semptomları en az birisi olan denekler dahil edildi. Diğer subgrup EAS için epigastrik ağrı veya epigastrik yanma şikayeti olan denekler dahil edildi (9).

PKOS ve kontrol denek grubuna önceki çalışmalarda kullanılan visual analog scale (VAS) kullanılarak mide belirtileri ile ilgili anket doldurmaları istendi. Bu ankette, deneklere 0-100 mm VAS üzerinde $0 \mathrm{~mm}$ "semptom yok" ve $100 \mathrm{~mm}$ "şiddetli semptom" olmak üzere postprandial doygunluk, erken doyma, epigastrik ağrı ve epigastrik yanma mide belirtilerinin şiddetini skorlaması istendi. Deneklerden bu skalada skoru 30 ve üzeri olanlar için semptomlar anlamlı olarak kabul edildi (10).

\section{Biyokimyasal Analiz}

Tüm katılımcılardan gece açlıktan sonra sabah 08:00 ve 09:00 arasında açlık kan glukozu (mg/dL), insülin $(\mu \mathrm{U} / \mathrm{mL})$, TSH 
( $\mu \mathrm{IU} / \mathrm{mL})$, FSH ve LH $(\mathrm{mIU} / \mathrm{mL})$, prolaktin $(\mathrm{ng} / \mathrm{mL})$, kortizol ( $\mu \mathrm{g} / \mathrm{dL})$, total testosteron $(\mathrm{ng} / \mathrm{dL})$ ve DHEAS $(\mu \mathrm{g} / \mathrm{dL})$ için venöz kan numuneleri alındı. Serum FSH, LH, total testosteron, prolaktin, DHEAS and TSH seviyeleri immun Beckman Coulter DxI 800 analizör ayraçlar kullanılarak immunoassay ile ölçüldü.

\section{İstatistiksel Analiz}

Çalışmamızdan elde edilen veriler SSPS (veri 22.0) programına yüklenerek verilerin değerlendirilmesinde bağımsız gruplarda iki ortalama arasındaki farkın önemlilik testi, Varyans Analizi, Tukey testi ve Ki-Kare testi kullanıldı. Tüm analizler için p değerinin < 0.05 olması anlamlı kabul edildi. Istatistiksel analizler SPSS version 22 software (SPSS Inc., Chicago, IL, USA) kullanılarak yapildı.

\section{BULGULAR}

Bu çalışmaya; 73 PKOS'lu ve 67 sağlıklı kontrol olmak üzere toplam 140 kadın denek alındı. Deneklerin, demografik ve biyokimyasal özellikleri Tablo l'de sunulmuştur. PKOS ve sağlıklı kontrol denekleri arasında yaş açısından istatistiksel

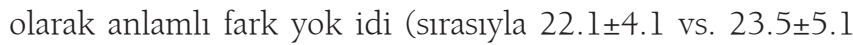
yaş p > 0.05). Çalışmada PKOS'lu hastalarda sağlıklı kontrol grubuna kıyasla VKI yüksek fakat istatistiksel olarak anlamlı

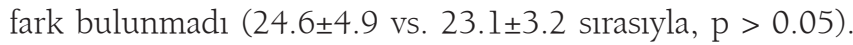
PKOS'lu hastalarda, sağlıklı kontrol deneklere göre serum kan şekeri, insülin, kortizol, prolaktin, TSH, FSH ve HOMA-IR indeksi yüksek olmasına rağmen aralarında istatistiksel fark yok idi ( $>0.05)$. PKOS'lu hastalar ve sağlıklı kontrol grubu denekler serum total testosteron (sirasiyla, $37.7 \pm 21.4$ vs. 25.4 \pm 11.1 ), DHEAS (sirasiyla $433.8 \pm 166.3$ vs. $269.5 \pm 95.9$ ) ve LH (sırasıyla $7.39 \pm 4.3$ vs. $6.06 \pm 2.8$ ) düzeyleri açısından karşılaştırıldığında aradaki fark önemli bulundu (sırasıyla, p: 0.001. p: 0.001, p: 0.038 ) (Tablo 1).

PKOS'lu hastalarda 73 hastanın 38'inde (\%52.1) ve sağlıklı kontrol grubunda ise 67 deneğin 16'sinda (\%23.9) FD mevcut idi. PKOS'lu hastalarda FD sıklığı sağlıklı kontrol grubuna klyasla istatistiksel olarak oldukça yüksek bulundu ( $\mathrm{p}<0.01)$. PKOS'lu hastalar FD subgrupları açısından karşılaştırıldığında PDS sıklığı sağlıklı kontrol grubuna göre istatistiksel olarak yüksek ( $\mathrm{p}<0.05)$ iken EAS sıklığı sağlıklı kontrol grubuna göre yüksek ancak aralarında istatistiksel fark yok idi ( $>0.05)$ (Tablo 2).

\section{TARTISQMA}

Bu prospektif çalışmamız, PKOS'lu hastalarda FD sıklı̆̆ını araştıran literatürdeki ilk çalışmadır. Çalışmamızda FD sıklığı, PKOS'lu hastalarda \%53 iken sağlıklı kontrol deneklerde \%28.4 saptandı. Türk toplumunda normal popülasyonda yapılan çalışmada FD sıklığı \%31-35 idi ve çalışmamızda sağlıklı kontrol deneklerde literatüre benzer sıklıkta bulundu (11).

Roma III kriterine göre yapılan çalışmalarda FD coğrafi farklılar göstermekle birlikte sıklığı yaklaşık \% 5-40 arasında değişir (12). Dünyada son on yılda özellikle gençlerde ve bayanlarda FD sıklığı artmaktadır (13). Bu hastalık yaşamı tehdit eden ve mortaliteye neden olan bir hastalık değildir. Bununla birlikte, FD sağlıklı yaşam kalitesini azaltır ve sağlık sistemi üzerine yüksek maliyetlere neden olur. Ayrıca FD hastalarında semptomların şiddetine bağlı olarak günlük aktivelerin ve yaşam kaliteleri azalır $(14,15)$. Bu hastalığın patofizyolojisi tam olarak anlaşılmamasına rağmen gastrik motilite bozuklukları, visseral hipersensivite, genetik, Helicobacter pylori, gastrik asid sekresyon artışı ve postinfeksiyöz gibi multifaktöriyel

Tablo 1. PKOS ve kontrol grubu deneklerinin demografik ve biyokimyasal özellikleri

\begin{tabular}{|l|c|c|c|}
\hline Değişkenler & PKOS Denekler $(\mathbf{n}=73)$ & Sağlıklı Kontroller $(\mathbf{n}=67)$ & 0.07 \\
\hline Yaş $($ ortalama \pm SD) $y l$ l & $22.1 \pm 4.1$ & $23.5 \pm 5.1$ & 0.06 \\
\hline Vücut kitle indeksi $\left(\mathrm{kg} / \mathrm{m}^{2}\right)$ & $24.6 \pm 4.9$ & $23.1 \pm 3.2$ & 0.347 \\
\hline Açlık şekeri $(\mathrm{mg} / \mathrm{dL})$ & $81.3 \pm 6.7$ & $84.8 \pm 7.8$ & 0.243 \\
\hline Açlık insülin $(\mu \mathrm{U} / \mathrm{mL})$ & $11.1 \pm 4.4$ & $10.2 \pm 4.3$ & 0.109 \\
\hline Kortizol $(\mu \mathrm{g} / \mathrm{dL})$ & $16.8 \pm 6.9$ & $14.9 \pm 6.1$ & 0.984 \\
\hline Prolaktin $(\mathrm{ng} / \mathrm{mL})$ & $20.4 \pm 12.9$ & $20.4 \pm 11.1$ & 0.196 \\
\hline TSH $(\mu \mathrm{IU} / \mathrm{mL})$ & $1.99 \pm 0.9$ & $2.20 \pm 1.1$ & 0.553 \\
\hline FSH $(\mathrm{mIU} / \mathrm{mL})$ & $6.04 \pm 2.4$ & $6.27 \pm 2.1$ & 0.038 \\
\hline LH $(\mathrm{mIU} / \mathrm{mL})$ & $7.39 \pm 4.3$ & $6.06 \pm 2.8$ & 0.001 \\
\hline Total testosteron $(\mathrm{ng} / \mathrm{dL})$ & $37.7 \pm 21.4$ & $25.4 \pm 11.1$ & 0.001 \\
\hline DHEAS $(\mu \mathrm{g} / \mathrm{dL})$ & $433.8 \pm 166.3$ & $269.5 \pm 95.9$ & 0.347 \\
\hline HOMA IR & $2.25 \pm 1.1$ & $2.08 \pm 0.9$ & \\
\hline
\end{tabular}

PKOS: Polikistik over sendromu, TSH: Troid uyarıcı hormon, LH: Luteinleștirici hormon, FSH: Folikül uyarıcı hormon, DHEAS: Dehidroepiandrosteron sülfat, HOMA IR: Homeostasis Model Assesment- Insülin Direnç Indeksi. Veriler ortalama \pm SD ifade edildi. 


\begin{tabular}{|l|c|c|c|}
\hline \begin{tabular}{l} 
Tablo 2. PKOS ve kontrol grupları arasında gastrointestinal semptomların karşılaştırılması. \\
\hline Semptom
\end{tabular} PKOS Denekler (n=73) & Sağlıklı Kontroller (n=67) & p \\
\hline Fonksiyonel dispepsi & $1.45 \pm 0.5$ & $1.70 \pm 0.4$ & 0.006 \\
\hline Postprandial doygunluk & $1.54 \pm 0.5$ & $1.75 \pm 0.4$ & 0.013 \\
\hline Erken doyma & $1.91 \pm 0.3$ & $2.01 \pm 0.1$ & 0.017 \\
\hline Epigastrik ağrısı & $1.61 \pm 0.5$ & $1.74 \pm 0.4$ & 0.140 \\
\hline Epigastrik yanma & $1.60 \pm 0.5$ & $1.74 \pm 0.4$ & 0.102 \\
\hline
\end{tabular}

PKOS: Polikistik over sendromu. Veriler ortalama \pm SD ifade edildi.

nedenlerin rol aldığı düşünülmektedir (16). Roma III kriterlerine göre FD subgrupları olan postprandiyal distres sendro$\mathrm{mu}$ (PDS) ve epigastrik ağrı sendromu (EAS) için patogenezis ve tedavi yaklaşımları farklılık gösterir. PDS patogenezisi için varsayılan ana mekanizma gecikmiş gastrik boşalma iken EAS için visseral hipersensivitedir. Fonksiyonel dispepside gecikmiş gastrik boşalmanın semptomları postprandial doygunluk, erken doyma, bulantı ve kusma iken visseral hipersensivitenin semptomu ise en sık epigastrik ağrı ve yanmadır. Ayrıca FD subgrupların tedavi yaklaşımları farklılık gösterir. PDS'lu hastalarda tedavide prokinetik ajanlar tercih edilirken EAS'da ise trisiklik antidepresan ilaçlar tercih edilir (17-19).

Fonksiyonel dispepside altta yatan birçok mekanizma düşünülmesine karşı ana mekanizma gecikmiş gastrik boşalmadır. Yapılan çalışmalarda bu mekanizmanın fonksiyonel dispepsili hastalarda sıklı̆̆ı \%50-60'a kadar ulaşır $(17,18)$. Kadınlarda FD'nin sık görülmesinin kesin nedeni bilinmemekle birlikte yapılan çalışmalarda gecikmiş gastrik boşalma, visseral uyaranlara karşı ağrı algılama fizyolojisindeki farklılıklar ve kadın seks hormonal değişiklere bağlı olabileceği düşünülmektedir (19-21).

Fonksiyonel gastrointestinal bozukluklardan irritabl barsak sendromu (IBS), gastroözofageal reflü hastalığı (GÖRH) ile VKI arasında pozitif korelasyon olduğu bilinmektedir. Ancak FD ile VKI arasındaki ilişki tarışmalıdır. Yapılan geniş çaplı çalışmalarda FD ile VKI indeksi arasında anlamlı ilişki saptanmamıştır. Ancak subgrup analizlerde morbid obez kadınlarda FD daha sı olduğu görülmüştür $(18,22)$. Çalışmamızda FD ile VKI arasında istatistiksel anlamlı fark bulunamadı. Ancak hasta sayısı yeterli olmadığından morbid obezler ile FD sıklığı arasındaki ilişki değerlendirilemedi.

Polikistik over sendromu üreme çağındaki kadınlarda görülen en sık hormonal bozukluktur. Bu sendromda hiperandrojenizm ve insülin rezistansı oldukça sık görülür. Aşırı androjen yapımı hiperinsülinemi ve insülin rezistansını artırır (23). Obez hastalarda insülin direnci ve hiperandrojenism normal bireylere oranla yüksektir (24). Ayrıca kronik hiperandrojenizm gida alımını artırarak hem obezite hem de fonksiyonel dispepsi sıklığı artışına neden olur (25). Çalışmamızda PKOS'lu hastalarda insülin direnci sağlıklı kont- rol deneklere göre yüksekti fakat aralarında istatistiksel fark bulunamadi.

Son zamanlarda PKOS'da çeşitli gastrointestinal hormonların gastrointestinal motilite üzerine etkisi ile ilgili araştırmalar artmıştır. Gastrointestinal hormonlardan özellikle ghrelin ve incretin gecikmiş gastrik boşalması mekanizmasında zıt etki gösterirler. Ghrelin hormonu gastrik boşalmayı hızlandırır fakat incretin hormonları gastrik boşalmayı yavaşlatır (25). Ghrelin hormonu mide fundusu P/D1 ve pankreas epsilon hücreleri tarafından salınır iştahı artırır ve gastrointestinal motiliteyi aktive eder. Incretin hormonları Glukagon benzeri peptid glukagon benzeri peptit-1 (GLP-1) ve gastrik inhibitör polipeptit (GIP) oluşur. Glukagon benzeri peptit ince barsak ve kolonda bulunan L hücreleri tarafından salınır. Bu hormon insülin sekresyonu etkinliğini arttırır ve gastrointestinal motiliteyi yavaşlatır. Gastrik inhibitör polipeptit duodenum ve jejenum $\mathrm{K}$ hücrelerinden salınır. Bu hormon karbonhidrat ve yağ metabolizmasını etkiler ve gastrik motiliteyi yavaşlatır $(25,26)$. Vrbikova ve arkadaşlarının yaptığı çalışmada GIP seviyesi PKOS'lu hastalarda kontrol grubuna klyasla daha yüksek bulunmuştur (27). Lin ve arkadaşları, GLP-1 seviyesi PKOS'lu hastalarda kontrol grubu ile karşılaştırdığında daha yüksek olduğunu saptamıştır. Ayrıca bu çalışmada obez ve zayıf PKOS'lular arasında GLP-1 seviyesi açısından anlamlı fark saptanmamıştır. Bu çalışmanın sonucu VKI bağımsız PKOS hastalarında GLP-1 seviyesinde artış olduğunu ortaya çıkarmıştır (28). Ghrelin seviyesi ile obezite ve insülin rezistansı arasında negatif korelasyon mevcuttur. Yapılan çalışmada PKOS hastalarında kilo kaybı birlikte açlık ghrelin düzeyinde artış olduğu bulunmuştur (29). Bazı çalışmalarda PKOS hastalarında androjen fazlalığının ghrelin düzeyini azaltdığı saptanmıştır $(30,31)$. Panidis ve arkadaşlarının yaptığı çalışmada hirsutizm ve ghrelin seviyesi arasında zıt korelasyon bulunmuştur. Aşırı androgen ve hiperinsulinizm, PKOS hastalarında ghrelin seviyelerini azaltıcı etki gösterir $(32,33)$. Sonuçta yapılan çalışmalarda PKOS hastalarında ghrelin azalırken, GLP-1 ve GIP'de ise artış olmaktadır.

Çalışmamızda olduğu gibi PKOS hastalarında normal popülasyona göre FD sıklığının artış nedeni, FD patogenezisinde ana rol oynayan ve PDS alt grubunda semptomlardan sorum- 
lu olan gecikmiş gastrik boşalmaya bağlı olabileceğini düşündürdü. Bunun nedeni PKOS hastalarında androjen artışı ile birlikte ghrelin seviyesi azalırken GLP-1 ve GIP'in artması ve buna bağlı gastrik boşalmanın yavaşlaması olabilir. Ayrıca bu durum hiperandrojenizmin, gastrointestinal hormonlar üzerinde gastrik motiliteyi yavaşlatıcı etkisine bağlı olabilir. Bu nedenle PKOS hastalarında androjen hormonlarının yüksek olması hiperandrojenizm ile FD sıklığının artışı arasındaki ilişkiyi göstermektedir.

Çalışmamız literatüre yeni bilgiler sağlamasına rağmen sınırlayıcı yanları mevcut idi. Çalışmamız prospektif çalışma olmasına rağmen denek sayısı yeterli olmadığından hiperandrojenizm ile FD'nin subgrupları arasındaki ilişki değerlendirilemedi. Bu nedenle daha geniş sayılı deneklerle yapılan çalışmalara gereksinim vardır. Ayrıca PKOS'lu fonksiyonel dispepsisi olan hastalarda hiperandrojenizm ile gastrointestinal hormonlar olan ghrelin ve incretin hormon düzeyleri arasındaki ilişkiyi inceleyen çalışmalara ihtiyaç vardır.

Sonuç olarak, FD sıklığı PKOS hastalarında normal popülasyona göre oldukça fazladır. PKOS hastalarında FD subgrubları açısından değerlendirildiğinde PDS sıklığı normal popülasyona oranla daha sık görülürken diğer subgrup olan EAS'da anlamlı farklılık yok idi. Bunun nedeni olarak hiperandrojenizmin gastrointestinal hormonlar aracılığıla gastrik boşalmayı geciktirmesi olduğunu düşündük. Bu nedenle PKOS hastalarının FD ve subgrup olan PDS açısından dikkatli değerlendirilmesi gereklidir. Ayrıca bu bulgular FD ve diğer fonksiyonel gastrointestinal bozukluklarm patofizyolojisinde cinsiyet ve hiperandrojenizmin etkilerini gelecek araştırmalar aracılığı ile daha fazla aydınlatabilir.

\section{KAYNAKLAR}

1. Sirmans SM, Pate KA. Epidemiology, diagnosis, and management of polycystic ovary syndrome. Clin Epidemiol. 2013;18(6):1-13.

2. Setji TL, Brown AJ. Polycystic ovary syndrome: update on diagnosis and treatment. Am J Med. 2014;127(10):912-9.

3. Trikudanathan S. Polycystic ovarian syndrome. Med Clin North Am. 2015; 99(1):221-35.

4. Mahadeva S, Goh KL. Epidemiology of functional dyspepsia: a global perspective. World J Gastroenterol. 2006;12(17):2661-6.

5. Tack J, Talley NJ. Functional dyspepsia symptoms, definitions and validity of the Rome III criteria. Nat Rev Gastroenterol Hepatol. 2013;10(3):134-41

6. Tack J, Masaoka T, Janssen P. Functional dyspepsia. Curr Opin Gastroenterol. 2011; 27(6): 549-57.

7. Rotterdam ESHRE/ASRM-Sponsored PKOSConsensus Workshop Group. Revised 2003 consensus on diagnostic criteria and longterm health risks related to polycystic ovary syndrome. Fertil Steril. 2004;81:19-25.

8. Fruzzetti F, Campagna AM, Perini D, Carmina E. Ovarian volume in normal and hyperandrogenic adolescent women. Fertil Steril. 2015; 104(1): 196-9.

9. Karamanolis GP, Tack J. Current management of functional dyspepsia: impact of Rome III subdivision. Ann Gastroenterol. 2012;25(2):96-99.

10. Wilder-Smith CH, Li X, Shen L, Cao Y, Ho KY, Wong RK. Dysfunctional endogenous pain modulation in patients with functional dyspepsia Neurogastroenterol Motil. 2014; 26(4): 489-98.

11. Saruc M, Ozden N, Turkel N, Ayhan S, Demir MA, Tuzcuoglu I, Akarca US, Yuceyar H. Functional dyspepsia: relationship between clinical subgroups and Helicobacter pylori status in Western Turkey. Braz J Med Biol Res. 2003; 36(6): 747-51.

12. Mahadeva S, Ford AC. Clinical and epidemiological differences in functional dyspepsia between the East and the West. Neurogastroenterol Motil. 2015;. doi: 10.1111/nmo.12657. [Epub ahead of print]

13. Olafsdottir LB, Gudjonsson H, Jonsdottir HH, Thjodleifsson B. Natural history of functional dyspepsia: a 10-year population-based study. Digestion. 2010;81(1):53-61.

14. El-Serag HB, Talley NJ. Health-related quality of life in functional dyspepsia. Aliment Pharmacol Ther 2003; 18: 387-93.

15. Lacy BE, Weiser KT, Kennedy AT, Crowell MD, Talley NJ. Functional dyspepsia: the economic impact to patients. Aliment Pharmacol Ther 2013; 38: 170-7.

16. Miwa H, Watari J, Fukui H, Oshima T, Tomita T, Sakurai J, Kondo T, Matsumoto T. Current understanding of pathogenesis of functional dyspepsia. J Gastroenterol Hepatol. 2011; 26(3): 53-60.

17. Talley NJ. Functional dyspepsia and the Rome criteria: a success story. Neurogastroenterol Motil. 2015;27(8):1052-6.

18. Le Pluart D, Sabaté JM, Bouchoucha M, Hercberg S, Benamouzig R, Julia C. Functional gastrointestinal disorders in 35,447 adults and their association with body mass index. Aliment Pharmacol Ther. 2015;41(8):758-67.

19. Ford AC, Bercik P, Morgan DG, Bolino C, Pintos-Sanchez MI, Moayyedi P. The Rome III criteria for the diagnosis of functional dyspepsia in secondary care are not superior to previous definitions. Gastroenterology. 2014;146(4):932-40.

20. Talley NJ, Locke GR, Lahr BD, Zinsmeister AR, Tougas G, Ligozio G, Rojavin MA, Tack J. Functional dyspepsia, delayed gastric emptying, and impaired quality of life. Gut. 2006;55(7):933-9.

21. Mayer EA, Naliboff B, Lee O, Munakata J, Chang L. Review article: gender-related differences in functional gastrointestinal disorders. Aliment Pharmacol Ther. 1999;13 Suppl 2: 65-9.

22. Bouchoucha M, Fysekidis M, Julia C, Airinei G, Catheline JM, Cohen R, Benamouzig R Body mass index association with functional gastrointestinal disorders: differences between genders. Results from a study in a tertiary center.J Gastroenterol. 2015 Aug 12. [Epub ahead of print])

23. Diamanti-Kandarakis E, Dunaif A. Insulin resistance and the polycystic ovary syndrome revisited: an update on mechanisms and implications. Endocr Rev. 2012;33(6):981-1030.

24. Lim SS, Norman RJ, Davies MJ, Moran LJ. The effect of obesity on polycystic ovary syndrome: a systematic review and meta-analysis. Obes Rev. 2013;14(2):95-109.

25. Ma J, Lin TC, Liu W. Gastrointestinal hormones and polycystic ovary syndrome. Endocrine. 2014;47(3):668-78.

26. Khoo J, Rayner CK, Feinle-Bisset C, Jones KL, Horowitz M. Gastrointestinal hormonal dysfunction in gastroparesis and functional dyspepsia. Neurogastroenterol Motil. 2010; 22 (12):1270-8

27. Vrbikova J, Hill M, Bendlova B, Grimmichova T, Dvorakova K, Vondra $\mathrm{K}$, Pacini G. Incretin levels in polycystic ovary syndrome. Eur J Endocrinol. 2008;159(2):121-7.

28. Lin T, Li S, Xu H, Zhou H, Feng R, Liu W, Sun Y, Ma J. Gastrointestinal hormone secretion in women with polycystic ovary syndrome: an observational study. Hum Reprod. 2015;30(11):2639-44. 
29. Moran LJ, Noakes M, Clifton PM, Wittert GA, Tomlinson L, Galletly C Luscombe ND, Norman RJ. Ghrelin and measures of satiety are altered in polycystic ovary syndrome but not differentially affected by diet composition. J Clin Endocrinol Metab. 2004;89(7):3337-44.

30. Pagotto U, Gambineri A, Vicennati V, Heiman ML, Tschöp M, Pasquali RPlasma ghrelin, obesity, and the polycystic ovary syndrome: correlation with insulin resistance and androgen levels. J Clin Endocrinol Metab. 2002;87(12):5625-9

31. Schöfl C, Horn R, Schill T, Schlösser HW, Müller MJ, Brabant G. Circulating ghrelin levels in patients with polycystic ovary syndrome. J Clin Endocrinol Metab. 2002; 87(10):4607-10.
32. Repaci A, Gambineri A, Pagotto U, Pasquali R. Ghrelin and reproductive disorders. Mol Cell Endocrinol. 2011;340(1):70-9.

33. Panidis D, Asteriadis C, Georgopoulos NA, Katsikis I, Zournatzi V, Karkanaki A, Saltamavros AD, Decavalas G, Diamanti-Kandarakis E. Decreased active, total and altered active to total ghrelin ratio in normal weight women with the more severe form of polycystic ovary syndrome. Eur J Obstet Gynecol Reprod Biol. 2010;149(2):170-4. 